\section{Rarely seen nasal congenital problems causing neonatal upper respiratory obstruction: a case series}

\author{
Yeşim Başal,1 Abdullah Bariş Akcan,2 \\ Yasemin Durum Polat, ${ }^{3}$ Ceren Günel, 1 \\ Aylin Eryilmaz, '1 Sema Başak \\ Departments of ${ }^{1}$ Ear, Nose, Throat-Head \\ and Neck Surgery, 2Pediatrics, \\ 3Radiology, Faculty of Medicine, Adnan \\ Menderes University, Aydın, Turkey
}

\section{Abstract}

Since newborns are obligatory nasal breathers, upper respiratory tract problems may sometimes be life threatening. The most common pathology causing dyspnea and stridor in newborns is laryngomalacia. Nasal cavity pathologies that risk the neonatal airway are more rarely met. These anomalies may be seen either as solitary anomalies or as a part of a syndrome. While choanal atresia is one of the best-known nasal cavity anomalies, choanal stenosis, congenital nasal mid-line masses, congenital nasal pyriform aperture stenosis, and nasal tip anomalies are more rarely seen structural pathologies. Choanal atresia may be present either as an isolated congenital anomaly or as a part of CHARGE syndrome. Some rare chromosome anomalies may also cause significant problems during nasal respiration in newborns. With this study, we presented a case series of newborns with pathologies that affected nasal respiration. Although the diagnosis and treatment of choanal atresia and congenital dacryocystocele are well known, the information on the diagnosis and treatment of the other two uncommon cases are limited. With this study, we aimed to contribute to the literature by presenting our approach in six cases having congenital pathologies that cause nasal respiratory obstruction.

\section{Introduction}

The most common pathology causing dyspnea and stridor in newborns is laryngomalacia. Choanal atresia is one of the best-known nasal cavity anomalies, while choanal stenosis, congenital nasal mid-line masses, congenital nasal pyriform aperture stenosis, and nasal tip anomalies are more rarely seen. ${ }^{1}$ Choanal atresia may be present alone or as a part of CHARGE syndrome. ${ }^{2}$

We present here six cases of congenital pathologies that cause nasal respiratory obstruction. The diagnosis and treatment of all cases were performed in Adnan Menderes University Medical Faculty Hospital (Turkey) between years of 2012 and 2015.

\section{Case Report \#1}

A 2-day-old baby girl was admitted with complaints of swelling of left eye, redness, and asphyxiation during feeding. In addition to swelling around her left eye punctum, in nasal examination, a cystic structure was identified, which fully obstructed the nasal passage in the inferior meatus. The white blood cell count of the patient was 11.000 . Following consultation of the patient with Ophthalmology Department, the patient was diagnosed with unilateral infected dacryocystocele. The patient recovered clinically, following administration of parenteral medical treatment (ampicillin-sulbactam $40 \mathrm{mg} / \mathrm{kg} /$ day) and punctual massage for ten days. The second year followup examination revealed normal findings.

\section{Case Report \#2}

A 10-day-old baby girl was admitted with complaints of difficulty in nasal breathing and swelling at the inner side the left eye. The inner canthus of the right eye was normal in inspection; however, there was a questionable hardness by palpation. Dense purulent discharge was detected within both nasal passages together with severe edema of the nasal mucosa. The white blood cell count of the patient was 14.800 . By ultrasonography, anechoic cystic lesion of approximately $12 \times 11 \mathrm{~mm}$ size, with smooth borders at the location of left epicanthus, and anechoic cystic lesion of approximately $8 \times 11 \mathrm{~mm}$ size, at the location of right epicanthus were identified. The patient was hospitalized in the neonatal service and treatment with IV ampicillin and cefotaxime was initiated. Since swelling and erythema at the inner side of the left eye decreased, drainage was not required. The patient was discharged following completion of the antibiotic treatment in ten days. The sixth month follow-up examination revealed normal findings.

\section{Case Report \#3}

A 20-day-old baby girl was admitted due to findings of upward and outward displacement of the left eye and redness with $2 \times 1 \mathrm{~cm}$ size at the inner canthus, and swelling sensitive to palpation (Figure 1A). The baby had a white blood cell count of 15.000 and she was hospital-
Correspondence: Yeşim Bașal, ENT-Head and Neck Surgery Department, Adnan Menderes University, Kepez Mevkii, 09010 Aydın, Turkey.

Tel.: +90.256.2145400.2721

E-mail: yesimdurgun@gmail.com

Key words: Congenital; choanal atresia; chromo some 18 deletion syndrome; nasolacrimal duct; nose.

Contributions: the authors contributed equally.

Conflict of interest: the authors declare that there is no conflict of interest regarding the publication of this paper.

Received for publication: 4 February 2016 .

Revision received: 16 February 2016.

Accepted for publication: 18 February 2016.

This work is licensed under a Creative Commons Attribution NonCommercial 4.0 License (CC BYNC 4.0).

(C) Copyright Y. Başal et al., 2016

Licensee PAGEPress, Italy

Pediatric Reports 2016; 8:6456

doi:10.4081/pr.2016.6456

ized in the neonatal intensive care unit. Her physical examination revealed a cystic structure with hyperemic appearance, which fully obstructed the passage and was bulging from inferior meatus to the left nasal passage. By magnetic resonance imaging (MRI), a cystic structure with smooth borders was detected in the neighborhood the left nasolacrimal duct. Antibiotic treatment was initiated by administration of ampicillin and cefotaxime. Surgical treatment was planned due to the upward and outward displacement of the eye. The cyst was marsupialized and Ritleng tube was placed under general anesthesia. Five and a half months later, the tube was removed and lavage revealed that the punctum was patent. The second year follow-up examination revealed normal findings.

\section{Case Report \#4}

A 20-day-old infant was admitted with complaints of swelling and deformity at the tip of the nose, together with difficulty in breathing during feedings. Both nostrils were narrow and asymmetrical (Figure 1B). A swelling with undefined borders was palpated at the nasal tip. A homogeneously hyperechoic $9 \times 8 \mathrm{~mm}$ sized lesion with smooth borders, located at the skin and the subcutaneous tissue on the right wing of nose, was identified by ultrasonography. A 10×8 mm sized mass lesion with 
smooth borders, which was hyperintense in T1A and T2A series, was suppressed in the fatsuppressed series, and not showing diffusion limitation, was identified on the right wing of the nose by magnetic resonance imaging. With the indication of respiratory distress affecting the nutrition of infant, the mass was removed by performing open rhinoplasty and using flap technique. The pathological diagnosis was reported as fibrolipomyomatous tissue. Infant sustained normal growth. At the second postoperative year follow-up examination, no difficulty was encountered during nasal respiration and follow-up was recommended.

\section{Case Report \#5}

The baby boy, born in an external center by optional cesarean section at 38 weeks of gestation with 3000 gr weight, was transferred to our hospital due to the diagnosis of an omphalocele. The omphalocele defect was closed by the Pediatric Surgery Department under emergency conditions. During the postoperative period, the baby encountered severe respiratory distress. Bilateral choanal atresia was detected by nasal endoscopic examination. The patient was radiologically diagnosed as osseomembranous choanal atresia and was urgently operated.

\section{Case Report \#6}

The baby girl was born at 38th week of first gestation of 20-year-old mother, with birth weight of 3145 grams. Dysmorphic facial features (rough-round faces, hypertelorism, large ears, micrognathia, flattened and broad nasal bridge), breathing by nasal flaring, tachypnea, and intercostal-subcostal retractions were detected by physical examination.

Due to increasing respiratory distress, the patient was intubated and connected to mechanical ventilator, following hospitalization to the intensive care unit. During followup after intubation, her tachypnea regressed and the baby was extubated on the second day. Following extubation, the patient's breathing was comfortable, but she was encountering cyanosis during feeding and significant subcostal retractions and inspiratory stridor were starting thereafter, respiratory acidosis was developing, necessitating the patient to be reintubated. The paranasal sinus computed tomography (CT) revealed that both posterior choanal apertures were normal (measured $5.08 \mathrm{~mm}$ at the right side, $6.56 \mathrm{~mm}$ at the left side). The postero-inferior width of vomer was increased (measured $4.8 \mathrm{~mm}$ ). The width of pyriform aperture was measured as $11 \mathrm{~mm}$. It was observed that nasal septum was thicker than normal and both nasal cavities were obliterated by soft tissue. Thereupon, short-term topical decongestant and nasal steroid treatments were recommended, in addition to nasal lavage. The infant breathed from time to time comfortably; however, sometimes intubation was required when the infant experienced recurrence of the respiratory problems. Since the baby did not benefit from medical treatment, it was decided to place tubes into the nasal passages. To place the tube, 1-2 mm cartilage was removed with a limited incision made on the existing septum deviation, and the deviated septum was pushed to the right side; by this way, the passage was completely opened, the choana became easily exposed, and the aspiration catheter (\#10 aspiration catheter) was placed (Figure 1C). The complaints of the infant, who was comfortable for the first two days following this procedure, started again, despite the aspiration probe was still in its place and open. 46XX,del(18)(11,2) was determined by the peripheral blood karyotype analysis (50 metaphase) which was made due to the dysmorphic facial appearance. Patient was discharged by planning close follow-up in terms of the growth and neuromotor development of the patient together with genetic counseling for the family.

\section{Discussion and Conclusions}

The congenital dacryocystocele is a rare pathology, seen in only $0.1 \%$ of infants with congenital nasolacrimal obstruction. ${ }^{3}$ Its typical appearance is a bluish, cystic, and hard mass, localized under the medial canthus. ${ }^{4}$ The clinical features of infection in this congenital cyst is described as dacryocystitis.5,6 Meningoencephalocele, hemangioma and dermoid cysts should be considered in differential diagnosis. ${ }^{7}$ If the general status of infant is suitable, conservative treatment should be tried first. Cyst marsupialization can be performed either as a single procedure or together with stent. ${ }^{8}$ Our first two cases had benefited from conservative approach.

In our third case, the surgery was directly performed, due to complete obstruction of nasal passage, severe displacement of the left eye, and periorbital cellulitis; Ritleng tube was inserted and was removed five and a half months later. Ritleng tube is recommended to be kept in place for 3-6 months. ${ }^{9,10}$

Ultrasound is used in diagnosis. This noninvasive diagnostic method allows the identification and differentiation of different masses. Additionally, it shows the content of dacryocystocele, such as fluids and debris. ${ }^{11}$ Cross-sectional image resolution (CT or MRI) might be requested to exclude complications for exam- ple periorbital or orbital cellulitis and underlying malignancy. ${ }^{12-14}$ Malignancy is rare in newborn. ${ }^{14}$

Neonatal nostril and/or nasal tip anomalies are very rare. These anomalies usually coexist with other nasal cavity anomalies such as choanal atresia and congenital nasal pyriform aperture stenosis. ${ }^{15,16}$ In our fourth case, the preoperative radiological diagnosis of the mass, which led to extreme prominence of the nasal tip together with narrowing and defor-

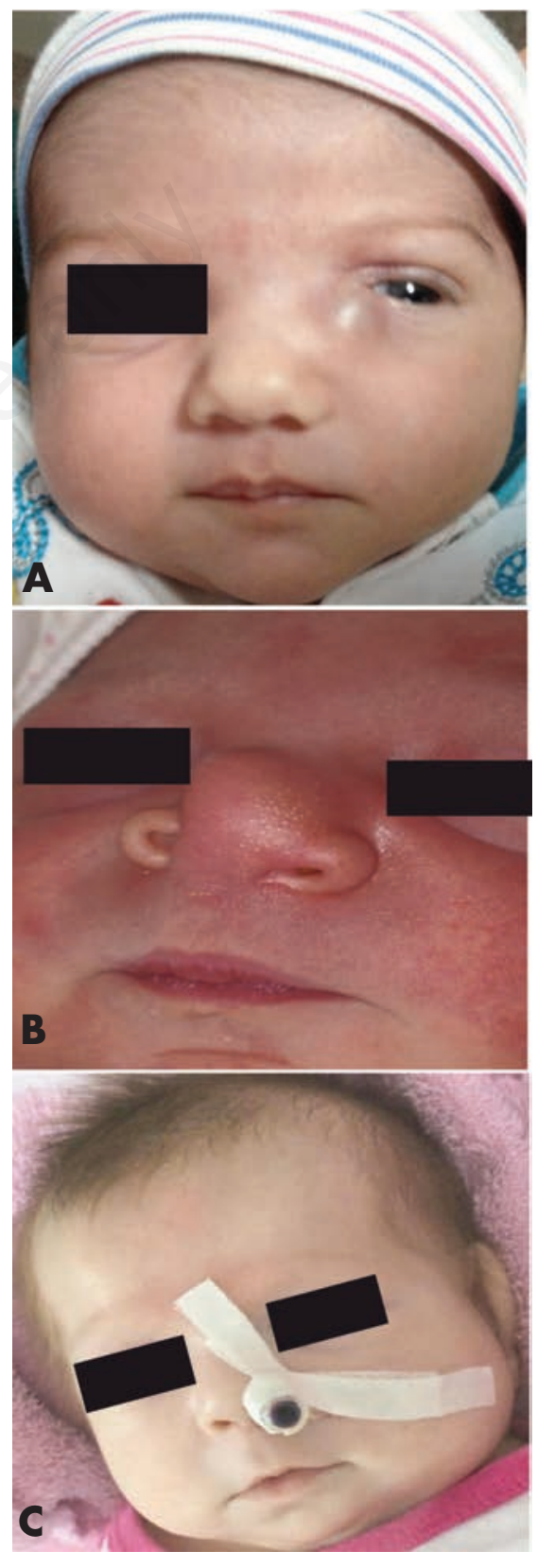

Figure 1. A) Redness swelling around left eye punctum; B) narrow and asymmetric nostrils, swelling with undefined borders on the nose; C) appearance of the patient with catheter postoperatively. 
mation of the nostril, was considered as dermoid cyst. Since it caused problems in nasal breathing especially while feeding, it was decided to remove the mass. Open Rhinoplasty and Flap Technique were chosen for the procedure. The pathological diagnosis of the mass was reported as atypical fibrolipomyomatous tissue. We encountered radiological atypical fibrolipomyomatous tissue located in the nasal dorsum, neither in newborns nor in other age groups, within the scope of the medical literature.

18 p deletion is a chromosome anomaly that may occur via hereditary transition or spontaneously. Its phenotypic features are not completely defined. ${ }^{17}$ It is characterized by findings of craniofacial dysmorphism such as mental retardation, growth retardation, dystonia, round face, prominent anti-helix of the ear, hypertelorism, tip-tilted nose and broad nasal bridge, micrognathia, high-arched palate, fish mouth, tooth abnormalities and anomalies of extremities, genitalia, brain, eye, and heart. 18,19 There are more than 100 cases in the literature. ${ }^{19}$ However, inspiratory stridor problem, which was life threating in our case, was not reported in any of these cases. In this respect, our case was the first case with lifethreatening upper respiratory tract obstruction during the neonatal period in the literature. We were not able to determine by which mechanism this chromosome anomaly causes lifethreatening respiratory problem. We suggest that dystonia might be one of the probable mechanisms.

Choanal atresia was first described by Roeder in $1755 .{ }^{20}$ Since it can be symptomatic very early and can also lead to severe respiratory distress when it is bilateral, making the diagnosis just following delivery has utmost importance. ${ }^{21}$ Various congenital anomalies may accompany in approximately $40-50 \%$ of patients with choanal atresia; however, ours was the first case that choanal atresia and omphalocele association was defined. Focusing primarily on the treatment of omphalocele had delayed the diagnosis of choanal atresia, despite the presence of respiratory distress. However, by clinical suspicion, endoscopic and radiological investigations, diagnosis was confirmed and surgery was performed. No matter which additional pathologies are present, the investigation for choanal atresia should not be delayed in newborns.

\section{References}

1. John DJ, Hernandez JA, Swischuck LE. Airway imaging in children In: Bailey BJ, Johnson JT, Newland SD, eds. Head and neck surgery otolaryngology. Philadelphia: Lippincott Williams and Wilkins; 2006. p 1072.

2. Kaplan LC. The CHARGE association: choanal atresia and multiple congenital anomalies. Otolaryngol Clin North Am 1989;22:661-72.

3. MacEven CJ, Young JD. Epiphora during the first year of life. Eye 1991;5:596-600.

4. Wong RK, VanderVeen DK. Presentation and management of congenital dacryocystocele. Pediatrics 2008;122:1108-12.

5. Ali MJ. Pediatric acute dacryocystitis. Ophthal Plast Reconstr Surg 2015;31:341-7

6. Barham HP, Wudel JM, Enzenauer RW, et al. Congenital nasolacrimal duct cyst/dacryocystocele: an argument for a genetic basis. Allergy Rhinol 2012;3:46-9.

7. Becker BB. The treatment of congenital dacryocystocele. Am J Ophthalmol 2006;142: 835-8.

8. Dogan E, Yüksel NG, Ecevit MC, et al. Microdebrider assisted endoskopic marsupializasyon of congenital intranasal nasolacrimal duct cysts. Int $\mathrm{J}$ Pediatr Otorhinolaryngol 2012;76:488-91.

9. Pelit A, Caylakli F, Yaycioglu RA, et al. Silicone intubation with the Ritleng method using intranasal endoscopy to treat congenital nasolacrimal duct obstruction. Int J Pediatr Otorhinolaryngol 2009;73:1536-8.

10 Yalaz M, Ozcan AA, Akcali C, et al. Lacrimal intubation with the Ritleng system in recurrent congenital nasolacrimal duct obstruction in children. ORL J Otorhinolaryngol Relat Spec 2004;66:35-7. 11. Machado MAC, Junior LA, Silva JAF, et al.
Congenital dacryocystocele: diagnosis using ante and post-natal ultrasonography. Arq Bras Oftalmol 2014;77:261-3.

12. LeBedis CA, Sakai 0. Vascular and other emergencies in the head. Nontraumatic orbital conditions: diagnosis with CT and MR imaging in the emergent setting. RadioGraphics 2008;28:1741-53.

13. Ludwig BJ, Foster BR, Saito N, et al. Diagnostic imaging in nontraumatic pediatric head and neck emergencies. RadioGraphics 2010;30:781-99.

14. Capps EF, Kinsella JJ, Gupta M, et al. Emergency imaging assessment of acute, nontraumatic conditions of the head and neck. RadioGraphics 2010;30:1335-52.

15. Abdollahifakhim S, Mousaviagdas M. Association of nasal nostril stenosis with bilateral choanal atresia: a case report. Iran J Otorhinolaryngol 2014;26:43-6.

16. Gungor AA, Reiersen DA. Balloon dilatation for congenital nasal piriform aperture stenosis (CNPAS): a novel conservative technique. Am J Otolaryngol 2014;35:43942.

17. Peng D, Long PP, Wen B, et al. A study of a rare chromosomal disorder: mosaic 46,XX,del(18)(p11.2)/46,XX,i(18q). J Genet 2013;92:611-5.

18. De Grouchy J, Lamy M, Thieffry S, et al. Dysmorphie complexe avec oligophre nie: Deletion des bras courts d'un chromosome 17-18. C R Acad Sci 1963;256:1028.

19. Wester U, Bondeson ML, Edeby C, et al. Clinical and molecular characterization of individuals with 18p deletion: a genotypephenotype correlation. Am J Med Genet 2006;140:1164-71.

20 Coniglio JU, Manzione JV, Hengerer AS. Anatomic findings and management of choanal atresia and the CHARGE association. Ann Otol Rhinol Laryngol 1998;97:448-53.

21. Brown OE, Smith T. The evaluation of choanal atresia by $\mathrm{CT}$. Int $\mathrm{J}$ Pediatr Otorhinolarygol 1986;12:85-98. 